\title{
Hopefulness Among Non-U.S.-Born Latino Youth and Young Adults
}

\author{
Sarah A. Stoddard, PhD, RN, CNP, and Carolyn M. Garcia, PhD, MPH, RN \\ Sarah A. Stoddard, PhD, RN, CNP, is Research Assistant Professor, Department of Health Behavior and Health Education, School of Public Health, \\ University of Michigan, Ann Arbor, Michigan. Carolyn M. Garcia, PhD, MPH, RN is Assistant Professor, School of Nursing, University of Minnesota, \\ Minneapolis, Minnesota, USA.
}

\section{Search terms:}

Adolescent, future thinking, hope, immigrant, Latino, mental health, young adult

\section{Author contact:}

sastodda@umich.edu,with a copy to the Editor: poster@uta.edu

doi: 10.1111/j.1744-6171.2011.00307.x
PROBLEM: U.S. Latino youths experience disproportionately high rates of health and social problems. There is a need to identify protective factors for reducing risky behaviors. Little is known about the protective nature of hope among immigrant Latino adolescents.

METHODS: This descriptive cross-sectional study examined hope and expectations for the future in non-U.S.-born Latino adolescents and young adults $(n=98)$ in urban and rural areas in the midwestern United States.

FINDINGS: Participants reported feeling hopeful about their future; however, differences were detected among subgroups.

CONCLUSION: Findings affirm the potential of hope as a protective factor for immigrant Latino adolescents and young adults. Nurses should be aware of hopefulness when implementing mental health preventive interventions. Research is needed to identify effective mechanisms for promoting and sustaining hope.
Hope has been defined as the anticipation of a future which is good, and reflects a belief that a personal tomorrow exists (Hinds, 1984; Miller \& Powers, 1988). Hope includes a belief in the ability to initiate and sustain actions toward goals, and the capacity to generate routes to reach goals (Snyder, Hoza, Pelham, \& Rapoff, 1997). During adolescence, a time of vast physical, emotional, and social development, a hopeful sense for the future can facilitate positive change and successful transition into adulthood. Without hope, some adolescents may not be concerned about risky behaviors that can adversely affect their future.

For adolescents of diverse ethnicities, higher levels of hope have been associated with scholastic achievement, social acceptance, feelings of self-worth, and overall psychological well-being (Adelabu, 2008; Ciarrochi, Heaven, \& Davies, 2007; Gilman, Dooley, \& Florell, 2006; Snyder et al., 1997; Valle, Huebner, \& Suldo, 2004). In contrast, low levels of hope, and feelings of hopelessness, have been associated with depression, school problems, and risk behaviors, including delinquency and violence, substance abuse, and risky sexual behavior (Bolland, 2003; DuRant, Getts, Cadenhead, \& Emans, 1995; Stoddard, Henly, Sieving, \& Bolland, 2010; Valle et al., 2004).

Despite the protective value of hope, and the potential harm of hopelessness, few studies have described the hope perceptions of Latino youths (Edwards, Ong, \& Lopez, 2007), and to our knowledge, none have examined hope among immigrant Latino youths. This is concerning as Latino youths in the United States experience disproportionately high rates of health and social problems, including suicidal ideation and attempts, pregnancy, substance use, school dropout, and poverty (Dogan-Ates \& CarrionBasham, 2007; Gonzales, Dumka, Deardorff, Carter, \& McCray, 2004; O’Donnell, O’Donnell, Wardlaw, \& Stueve, 2004; Ojeda, Patterson, \& Strathdee, 2008; Okamoto, RittOlson, Soto, Baezconde-Garbanati, \& Unger, 2009). For example, up to $40 \%$ of Latino youths are dropping out of high school (Pew Research Center, 2004). Furthermore, one in five adolescent girls report depressive symptoms in the past 2 weeks, but among Latino girls, the rate is twice as high (almost 40\%) (Centers for Disease Control and Prevention $[C D C], 2008)$. Latino youths also represent the fastest-growing U.S. subpopulation, moving toward a one in four proportion by 2050. These youths represent many of the future parents and workforce in the United States. There is a need, therefore, to identify and understand the role of protective factors, including hope, as potential mechanisms for reducing risky health behaviors among immigrant Latino adolescents. 
The purpose of the current study is to describe hope perceptions and expectations for the future in non-U.S.-born Latino adolescents (age 12-17) and young adults (age 18-24). Differences between urban- and rural-based adolescents and young adults by sex and age were examined. Differences by sex were also examined within each subgroup (i.e., urban and rural).

\section{Methods}

This secondary analysis used data from the "Emotional Health Survey," an instrument developed to assess levels of mental health knowledge and cultural beliefs among Latino youths and adults located in urban and rural settings within a Midwestern state (Garcia et al., 2008).

\section{Original Study}

Using a community-based participatory research approach (Israel et al., 2003; Minkler \& Wallerstein, 2003), the original study used a 100-item bilingual paper-pencil instrument to ascertain the mental health-related knowledge, attitudes, and behaviors of Latino youths and adults (Garcia et al., 2008). Conducted in a midwestern state experiencing rapid Latino population growth, the purpose of the original study was to describe Latino respondents' knowledge, attitudes, and behaviors to inform prevention efforts addressing mental health problems (Garcia et al., 2010). Study protocols were approved by the University of Minnesota Institutional Review Board (IRB). Participants were recruited through existing community programs, public charter schools, and community clinics serving the Latino community in a rural and an urban location in the state. Study recruitment procedures varied slightly between the urban and rural settings; however, most participants completed the Spanish version of the survey in either a community location (i.e., school, clinic, or community-based agency) or in their home. All participants provided written assent or consent. For the urban participants, the IRB approval included a waiver of active parental consent in lieu of parent notification. Therefore, youths less than 18 years of age were required to wait a few days before completing the questionnaire to ensure parents had time to contact the research team with questions or concerns. All urban participants received a $\$ 10.00$ gift card for survey completion. The ruralbased coinvestigators felt strongly that participants engage in research without an offered incentive, so the rural participants did not receive an incentive for survey completion. For additional information on study procedures, recruitment, inclusion/exclusion criteria, and response rates, see Garcia et al. (2010).
For this secondary analysis, a subsample was identified based on self-reported age (age 12-17 or 18-24) and selfreported immigrant status (being born outside of the United States) $(n=98)$.

\section{Measures}

\section{Hope Perceptions and Future Expectations}

Four independent items were used to capture participant's hopefulness about the future and expectations about their future (Table 2). Participant's hopefulness about their future was measured with a single item: Are you hopeful about your future? Response options were on a 3-point scale ranging from 0 (Not at all hopeful) to 2 (Very hopeful). Participant's worry about their future was measured with a single item: Are you worried about your future? Response options were on a 3-point scale ranging from 0 (Not at all worried) to 2 (Very worried). Participant's perception that they would reach their dreams was assessed with a single item: Do you feel you can reach your dreams for the future? Response options were on a 3-point scale ranging from 0 (Almost no chance) to 2 (Almost certain). Participant's perception of their risk for an early death was measured with a single item: What is the chance you will be killed by age 21? Response options were on a 3-point scale ranging from 0 (Almost no chance) to 2 (Almost certain). Low reliability $(\alpha=.29)$ prevented examining the items as a scale, so items were analyzed independently (Note: these items, to our knowledge, have never been constructed in scale format).

\section{Demographic Characteristics}

Urban and rural settings were determined based on geographic density and population size. The population total for the urban community was approximately 281,262 ; the total population for the rural community was approximately 24,958. Participants reported age (How old are you?) and sex ( male $=0$, female $=1)$.

An individual was characterized as Latino if they self reported "Latino" as their ethnic identification; an individual could also self-identify as another ethnicity, but these data were not collected in the original study (e.g., someone may self-identify as Latino and African American). All participants in this analysis self-identified as Latino.

An immigrant was defined as born outside of the United States. Participants were asked to report where they were born, and only those participants who identified as being born in another country were included in this analysis.

\section{Analysis}

Analysis of variance was used to test for differences between urban- and rural-based adolescents and young adults by sex 
and age for each of the hope perception and future expectation items. For each item, differences by sex were also tested within each subgroup (i.e., urban and rural). Analysis was completed using Stata 10.0 (Statacorp, 2007).

\section{Findings}

The total sample consisted of 98 immigrant Latino adolescents (age $12-17 ; M=15.65$ years) and young adults (age
18-24; $M=20.78$ years) (see Table 1). Forty-four percent $(n=35)$ of the sample indicated they were very hopeful about their future, and one in four $(25 \% ; n=24)$ were certain that they would reach their dreams. Twenty-six percent $(n=21)$ of the sample reported being not too worried about their future. Over half $(58 \% ; n=32)$ felt that they would not be killed by the age of 21 .

Overall, the youths in this study reported moderate levels of hopefulness about their future $[M=1.36$, standard devia-

\begin{tabular}{|c|c|c|c|}
\hline Characteristic & $\begin{array}{l}\text { Urban }(n=54) \\
n(\% \text { of total } \\
\text { sample) }\end{array}$ & $\begin{array}{l}\text { Rural }(n=44) \\
n(\% \text { of total } \\
\text { sample) }\end{array}$ & $\begin{array}{l}\text { Total }(n=98) \\
n(\% \text { of total } \\
\text { sample) }\end{array}$ \\
\hline \multicolumn{4}{|l|}{ Age (years) } \\
\hline $12-17$ & $21(21)$ & $19(19)$ & $40(41)$ \\
\hline $18-24$ & $33(34)$ & $25(26)$ & $58(59)$ \\
\hline \multicolumn{4}{|l|}{ Sex } \\
\hline Male & $27(28)$ & $29(30)$ & $56(57)$ \\
\hline Female & $27(28)$ & $15(43)$ & $42(43)$ \\
\hline \multicolumn{4}{|c|}{ Years in the United States } \\
\hline$\leq 1$ year & $14(14)$ & $4(4)$ & $17(17)$ \\
\hline $2-4$ years & $12(12)$ & $14(14)$ & $26(27)$ \\
\hline $5+$ years & $28(29)$ & $25(26)$ & $53(54)$ \\
\hline Not indicated & 0 & $1(1)$ & $1(1)$ \\
\hline \multicolumn{4}{|l|}{ Country of origin } \\
\hline Ecuador & $1(1)$ & 0 & $1(1)$ \\
\hline El Salvador & $5(5)$ & $2(2)$ & $7(7)$ \\
\hline Guatemala & $1(1)$ & $2(2)$ & $3(3)$ \\
\hline Honduras & $2(2)$ & $3(3)$ & $5(5)$ \\
\hline Peru & $1(1)$ & 0 & $1(1)$ \\
\hline Mexico & $43(44)$ & $37(38)$ & $80(82)$ \\
\hline Not indicated & $1(1)$ & 0 & $1(1)$ \\
\hline
\end{tabular}

Table 1. Demographic Characteristics

\begin{tabular}{|c|c|c|c|c|c|}
\hline \multirow[b]{2}{*}{ Survey items } & \multirow[b]{2}{*}{ Age } & \multicolumn{2}{|l|}{ Urban } & \multicolumn{2}{|l|}{ Rural } \\
\hline & & $\begin{array}{l}\text { Male } \\
M(S D)\end{array}$ & $\begin{array}{l}\text { Female } \\
M(S D)\end{array}$ & $\begin{array}{l}\text { Male } \\
M(S D)\end{array}$ & $\begin{array}{l}\text { Female } \\
M(S D)\end{array}$ \\
\hline \multirow{2}{*}{$\begin{array}{l}\text { Hopeful about your future? } \\
\qquad(0=\text { "not at all hopeful"; } \\
2=\text { "very hopeful") }\end{array}$} & $12-17$ & $1.00(0.71)$ & $1.43(0.79)$ & $1.43(0.65)$ & $1.60(0.55)$ \\
\hline & $18-24$ & $1.50(0.53)^{d}$ & $1.10(0.74)$ & $1.60(0.51)$ & $1.20(0.42)^{a}$ \\
\hline \multirow{2}{*}{$\begin{array}{l}\text { Worried about your future? } \\
\qquad(0=\text { "not at all worried"; } \\
2 \text { = "very worried") }\end{array}$} & $12-17$ & $0.89(0.60)$ & $0.86(0.69)$ & $0.86(0.66)$ & $0.40(0.55)$ \\
\hline & $18-24$ & $1.30(0.68)$ & $0.50(0.53)^{b}$ & $1.00(0.54)$ & $0.90(0.57)$ \\
\hline \multirow{2}{*}{$\begin{array}{l}\text { Feel you can reach dreams for } \\
\text { the future? }(0=\text { "almost no } \\
\text { chance"; } 2=\text { "almost } \\
\text { certain") }\end{array}$} & $12-17$ & $1.20(0.42)$ & $1.27(0.65)$ & $1.14(0.36)$ & $0.80(0.45)$ \\
\hline & $18-24$ & $1.38(0.50)$ & $1.19(0.40)$ & $1.27(0.46)$ & $1.30(0.48)$ \\
\hline $\begin{array}{l}\text { Chance you will be killed by } \\
21 ?(0=\text { "almost no }\end{array}$ & $12-17$ & $0.60(0.52)$ & $0.09(0.30)^{a, c}$ & $0.36(0.50)$ & $0.60(0.55)$ \\
\hline $\begin{array}{l}\text { chance"; } 2=\text { "almost } \\
\text { certain") }\end{array}$ & $18-24$ & $0.60(0.52)$ & $0.33(0.58)$ & 0 & $1.00(.52)$ \\
\hline
\end{tabular}

Table 2. Mean Scores for Immigrant Latino Youths and Young Adults on Futuristic Thinking by Geography, Sex, and Age Group

aSignificant difference by sex within age group and geographic region $(p<.05) ;{ }^{b}(p<.01)$.

cSignificant difference by sex across geographic region $(p<.05)$.

dSignificant difference by age with age group and geographic region $(p<.10)$. 
tion $(S D)=0.62]$, and felt they had some chance of meeting their dreams $(M=1.23, S D=0.47)$. On average, participants were somewhat worried about their future $(M=0.88, S D=$ 0.62 ), and most felt that they would not be killed by the age of $21(M=0.42, S D=0.50)$.

\section{Differences by Subgroup}

\section{Gender Differences Within Geographic Regions}

Urban young adult males were significantly more worried about their futures than their female counterparts $(F=8.73$, $p<.01)$. Urban adolescent males also felt that they were more likely to be killed by age 21 than urban adolescent females $(F=7.80, p<.05)$ (Table 2$)$. Rural young adult females were significantly less hopeful about their futures than rural young adult males $(F=4.25, p<.05)$. There were no significant differences observed for measures of hopefulness about the future or reaching future dreams.

\section{Gender Differences Between Geographic Regions}

Between the geographic regions, rural adolescent females felt that they were more likely to be killed by age 21 than their urban female adolescent counterparts $(F=5.91, p<.05)$ (see Table 2). There were no significant differences observed for measures of hopefulness about the future, reaching future dreams, or worry about the future.

\section{Age Differences Within Geographic Regions}

While there were no significant differences observed for measures of hopefulness about the future or reaching future dreams, trends toward significance were detected in hopefulness about the future (see Table 2). Urban young adult males were more hopeful than their younger adolescent male counterparts $(F=3.10, p<.09)$.

\section{Discussion}

Across the United States, Latino youths report rates of suicidal ideation, suicidal attempts, and depressive symptoms that consistently surpass their peers (CDC, 2008). Although national- and state-level data do not distinguish between U.S.-born and immigrant Latino youths, there are studies demonstrating differences in risks and outcomes for Latino youth subgroups (e.g., birth country, language use, length of time in the United States, and generation status) (Eitle, Wahl, \& Aranda, 2009; Garcia et al., 2008; Smokowski, DavidFerdon, \& Stroupe, 2009). Data are often conflicted, yet there is evidence that immigrant Latino youths benefit from cultural values and close ties to family (Loukas \& Prelow, 2004; O’Donnell et al., 2004; Potochnick \& Perreira, 2010). Our study findings support earlier research reporting that being a recent immigrant may offer a level of protection to Latino youths (Cook, Alegria, Lin, \& Guo, 2009; Harker, 2001; Harris, 1999; Pena et al., 2008). Most participants reported feeling quite hopeful about their future, perhaps reflecting immigration-related hopes and dreams (e.g., quality education, opportunity).

However, hopeful futuristic thinking was not consistent among respondent subgroups. It is plausible that the disproportionate rates of worry about the future and being killed observed among urban males reflect a greater impact of exposure to violence or gang activity than what their female counterparts experience. Prior research demonstrates that Latino adolescent males describe external stressors such as gang activity and substance use, whereas females more commonly indicate stressors associated with peer and parental relationships (Carvajal, Hanson, Romero, \& Coyle, 2002; Garcia \& Lindgren, 2009; Kobus \& Reyes, 2000). Up to 40\% of Latino males drop out of high school (Pew, 2004); worry about the future could reflect limited economic opportunities available to these young men combined with high expectations for financial contribution to the family in the United States and in their home country. While family closeness and family routines have been identified as protective against risk behaviors and poor mental health for Latino youths (Loukas \& Prelow, 2004; O’Donnell et al., 2004; Potochnick \& Perreira, 2010), family-related stressors are commonly reported by Latino adolescents (de Anda et al., 2000). For Latino males, these stressors may come from cultural expectations of providing income to the family, whereas females report familyrelated stressors related to greater parental restrictions (i.e., more restrictive curfews, less social freedom than male youths) (Gallegos-Castillo, 2006; Torres Stone \& Meyler, 2007).

Geographically, many immigrant Latino males reside in rural communities where job opportunities exist. Across the United States, there are migrant and nonmigrant employment opportunities available in agriculture, processing, and manufacturing (Kandel \& Cromartie, 2004). For the rural immigrant Latino males in this study, gained income in the United States could be contributing to their high levels of hopefulness toward the future. Generally, rates of gangrelated violence or similar risks that might counter feelings of hope are lower in rural settings than in urban, although there is growth in gang activity everywhere (National Gang Intelligence Center, 2009). Even so, it is unclear why the rural, immigrant Latino young adult females were not as hopeful as their male peers; one might surmise that employment or educational opportunities are more limited for females, although this requires more research.

Our study findings reinforce that Latino females are more likely than their male counterparts to report mental health risks, yet reasons for this are somewhat unclear. Certainly, the social context in which these youths live, and the social net- 
works available, may contribute to feelings of hopefulness or worry. The rural Latino females, regardless of their age category, appear to be experiencing relatively worrisome feelings of negativity toward the future. Not only were the young adult females less hopeful than their male counterparts, more rural younger adolescent females reported being more worried about being killed before they reached 21 years of age than the urban adolescent females. This is intriguing because one might initially assume that urban Latino females experience higher rates of exposure to violence or similar risk factors than rural Latino females. Yet, rural females may in fact be experiencing exposure to violence (i.e., domestic violence, dating violence) that could, in part, explain their worry about being killed before they reach their 21st birthday. Our findings for rural immigrant Latino females may reflect mental health problem trends and related risks for depression, selfharm, or other serious sequelae. National- and state-level data affirm the need for attention toward the mental health of Latino females in particular, regardless of geographic residence.

Nurses providing mental health care for immigrant Latino adolescents and young adults may cautiously use these study findings to support intervention efforts. For example, sessions with female Latino youths in one-to-one or group formats might explore unique factors contributing to lower levels of perceived hope in their lives. These discussions may elucidate potential ways in which nurses can help address these factors or offset them with protective interventions. Close family involvement in healthcare interactions, including mental health care, is common for many Latino families. It may be necessary for nurses, particularly those employed in rural settings, to closely consider the presence of risk and protective factors in the family setting prior to determining the plan of care for an immigrant Latino adolescent, female or male. Latino adolescent females are particularly susceptible to family-based stressors, including conflict with their mothers (Zayas, Gulbas, Fedoravicius, \& Cabassa, 2010). Nurses who understand this, in the context of feelings of hope and future among these girls, may be more successful in designing and offering mental health promotion or preventive intervention strategies. Finally, nurses should be encouraged by the study finding that many of these immigrant Latino youths were hopeful about their future. This provides an important foundation upon which nurses can build and encourage protective factors that foster resilience, an important attribute amid the stressors commonly experienced by immigrant youths in the United States.

Several limitations should be noted. First, these preliminary findings are based on a cross-sectional study with a relatively small sample of non-U.S.-born Latino youths and young adults; thus, we cannot assert that the associations reported are causal. Second, we do not account for how long the study participants have resided in their respective urban or rural residence, nor do we know about their previous experiences residing in either urban or rural environments. Third, we do not account for important immigration-related variables (e.g., documentation status, reasons for migration to the United States). Finally, we used four single items to represent a sense of hopefulness about the future. These items were created for this survey (Garcia et al., 2010), have not been used in previous research, and have not undergone validity testing. Future research should be conducted with measures validated specifically to assess the concept of hope (i.e., Children's Hope Scale, Snyder et al., 1997). Despite these limitations, our study offers insight into the hope perception and future expectations of immigrant youths and young adults.

Future research is needed to replicate these preliminary data, with particular attention given to the social ecological context in which these immigrant Latino youths reside. More research is needed exploring the relationship between hope for the future and mental health among Latino youths. Longitudinal studies would provide useful insights regarding the mental health and futuristic thinking trajectories of immigrant Latino youths as they age and transition into adulthood. The U.S. demographic growth trajectory-Latino youths already represent up to $50 \%$ of the students in some schools, and will soon comprise $25 \%$ of the overall U.S. population (U.S. Census Bureau, 2008)—demands that the mental health and futuristic thinking of Latino youths be carefully understood to inform and optimize health promotion interventions. As future workforce contributors, and parents to next generations, immigrant Latino youths' hope toward the future is critically important. Factors that threaten hopeful, futuristic thinking need to be known, and addressed, for immigrant Latino youths.

\section{Acknowledgments}

The authors wish to thank the Latino youth who participated in the original study for sharing their feelings. Dr. Stoddard was previously supported by the University of Michigan School of Nursing's Health Promotion/Risk Reduction Interventions with Vulnerable Populations Training Program (Project No.: 5T32NR007073-18, Principal Investigator: Antonia M. Villarruel). The views expressed in this paper do not necessarily reflect those of NINR.

\section{References}

Adelabu, D. (2008). Future time perspective, hope, and ethnic identity among African American adolescents. Urban Education, 43, 347-360.

Bolland, J. M. (2003). Hopelessness and risk behavior among adolescents living in high-poverty inner-city neighborhoods. Journal of Adolescence, 26, 145-158. 
Carvajal, S. C., Hanson, C. E., Romero, A. J., \& Coyle, K. K. (2002). Behavioral risk factors and protective factors in adolescents: A comparison of Latinos and Non-Latino Whites. Ethnicity \& Health, 7, 181-193.

Centers for Disease Control and Prevention. (2008). Youth risk behavior surveillance-United States, 2007. Morbidity \& Mortality Weekly Reports, 57(SS-4), 1-131.

Ciarrochi, J., Heaven, P. C. L., \& Davies, F. (2007). The impact of hope, self-esteem, and attribution style on adolescents' school grades and emotional well-being: A longitudinal study. Journal of Research in Personality, 41, 1161-1178.

Cook, B., Alegria, M., Lin, J. Y., \& Guo, J. (2009). Pathways and correlates connecting Latinos' mental health with exposure to the United States. American Journal of Public Health, 99, 2247-2254.

de Anda, D., Baroni, S., Boskin, L., Buchwald, L., Morgan, J., Ow, J., ... Weiss, R. (2000). Stress, stressors and coping among high school students. Children and Youth Services Review, 22, 441-463.

Dogan-Ates, A., \& Carrion-Basham, C. Y. (2007). Teenage pregnancy among Latinas: Examining risk and protective factors. Hispanic Journal of Behavioral Sciences, 29(4), 554-569.

DuRant, R. H., Getts, A., Cadenhead, C., \& Emans, S. J. (1995). Exposure to violence and victimization and depression, hopelessness and purpose in life among adolescents living in or around public housing. Journal of Developmental and Behavioral Psychology, 16, 233-237.

Edwards, L. M., Ong, A. D., \& Lopez, S. J. (2007). Hope measurement in Mexican American youth. Hispanic Journal of Behavioral Sciences, 29, 225-241.

Eitle, T. M., Wahl, A. G., \& Aranda, E. (2009). Immigrant generation, selective acculturation, and alcohol use among Latina/o adolescents. Social Science Research, 38, 732-742.

Gallegos-Castillo, A. (2006). La Casa: Negotiating family cultural practices, constructing identities. In J. Denner \& B. L. Guzman (Eds.), Latina girls: Voices of adolescents strength in the United States (pp. 44-58). New York: NYU Press.

Garcia, C., Gilchrist, L., Campesino, C., Raymond, N., Naughton, S., \& Patino, J. (2008). Using community-based participatory research to develop a bilingual mental health survey for Latinos. Progress in Community Health Partnerships: Research, Education and Action, 2(2), 105-120.

Garcia, C., Leite, A., Vazquez, G., Gilchrist, L., Skay, C., \& Raymond, N. (2010). Urban and rural immigrant Latino youths' and adults' knowledge and beliefs about mental health resources. Journal of Immigrant and Minority Health, 13, 500-509.

Garcia, C., \& Lindgren, S. (2009). "Life Grows Between the Rocks" Latino adolescents' and parents' perspectives on mental health stressors. Research in Nursing and Health, 32(2), $148-162$.

Gilman, R., Dooley, J., \& Florell, D. (2006). Relative levels of hope and their relationship with academic and psychological indicators among adolescents. Journal of Social \& Clinical Psychology, 25, 166-178.
Gonzales, N. A., Dumka, L. E., Deardorff, J., Carter, S. J., \& McCray, A. (2004). Preventing poor mental health and school dropout of Mexican American adolescents following the transition to junior high school. Journal of Adolescent Research, 19(1), 113-131.

Harker, K. (2001). Immigrant generation, assimilation and adolescent psychological well-being. Social Forces, 79, 969-1004.

Harris, K. (1999). The health status and risk behaviors of adolescents in immigrant families. In D. J. Hernandez (Ed.), Children of immigrants: Health, adjustment and public assistance (pp. 286-347). Washington, DC: National Academy Press.

Hinds, P. S. (1984). Inducing a definition of "hope" through the use of grounded theory methodology. Journal of Advanced Nursing, 9, 357-362.

Israel, B., Schulz, A. J., Parker, E. A., Becker, A. B., Allen, A. J., \& Guzman, J. R. (2003). Critical issues in developing and following community based participatory research principles. In M. Minkler \& N. Wallerstein (Eds.), Community-based participatory research for health (1st ed., pp. 53-76). San Francisco, CA: Jossey-Bass.

Kandel, W., \& Cromartie, J. (2004). New patterns of Hispanic settlement in rural America (RDRR-99) economic research service. United States Department of Agriculture. Retrieved from http://www.latinamericanstudies.org/latinos/ hispanic-settlement.pdf

Kobus, K., \& Reyes, O. (2000). A descriptive study of urban Mexican American adolescents' perceived stress and coping. Hispanic Journal of Behavioral Sciences, 22, 163-178.

Loukas, A., \& Prelow, H. M. (2004). Externalizing and internalizing problems in low-income Latino early adolescents: Risk, resource, and protective factors. Journal of Early Adolescence, 24, 250-273.

Miller, J. F., \& Powers, M. J. (1988). Development of an instrument to measure hope. Nursing Research, 37, 6-10.

Minkler, M., \& Wallerstein, N. (Eds.). (2003). Community-based participatory research for health (1st ed.). San Francisco: Jossey-Bass.

National Gang Intelligence Center. (2009). National gang threat assessment (Document ID: 2009-M0335-001). Washington, DC: National Gang Intelligence Center. Retrieved August 24, 2010, from http://www.justice.gov/ndic/pubs32/32146/ gangs.htm

O’Donnell, L., O’Donnell, C., Wardlaw, D. M., \& Stueve, A. (2004). Risk and resiliency factors influencing suicidality among urban African American and Latino youth. American Journal of Community Psychology, 33(1-2), 37-49.

Ojeda, V. D., Patterson, T. L., \& Strathdee, S. A. (2008). The influence of perceived risk to health and immigration-related characteristics on substance use among Latino and other immigrants. American Journal of Public Health, 98(5), 862-868. Okamoto, J., Ritt-Olson, A., Soto, D., Baezconde-Garbanati, L., \& Unger, J. B. (2009). Perceived discrimination and substance use among Latino adolescents. American Journal of Health Behavior, 33(6), 718-727. 
Pena, J. B., Wyman, P. A., Brown, C. H., Mattieu, M. M., Olivares, T. E., Hartel, D., \& Zayas, L. H. (2008). Immigration generation status and its association with suicide attempts, substance use, and depressive symptoms among Latino adolescents in the USA. Prevention Science, 9, 299-310.

Pew Research Center. (2004). Latino teens staying in high school: A challenge for all generations. Pew Hispanic Center Fact Sheet.

Potochnick, S. R., \& Perreira, K. M. (2010). Depression and anxiety among first-generation immigrant Latino youth. Journal of Nervous and Mental Disease, 198, 470-477.

Smokowski, P. R., David-Ferdon, C., \& Stroupe, N. (2009). Acculturation and violence in minority adolescents: A review of the empirical literature. Journal of Primary Prevention, 30, 215-263.

Snyder, C. R., Hoza, B., Pelham, W. E., \& Rapoff, M. (1997). The development and validation of the children's hope scale. Journal of Pediatric Psychology, 22, 399-421.

Statacorp, L. P. (2007). Stata release 10. College Station, TX: Statacorp LP.
Stoddard, S. A., Henly, S. J., Sieving, R. E., \& Bolland, J. (2010). Social connections, trajectories of hopelessness, and serious violence in impoverished urban youth. Journal of Youth and Adolescence, 40, 278-295. doi: 10.1007/s10964-010-9580-z.

Torres Stone, R. A., \& Meyler, D. (2007). Identifying potential risk and protective factors among non-metropolitan Latino youth: Cultural implications for substance use research. Journal of Immigrant Health, 9, 95-107.

U.S. Census Bureau. (2008). U. S. Hispanic population surpasses 45 million: Now 15 percent of total. Retrieved from http:// www.census.gov/newsroom/releases/archives/ hispanic_origin_population/

Valle, M. F., Huebner, E. S., \& Suldo, S. M. (2004). Further evaluation of the Children's Hope Scale. Journal of Psychoeducational Assessment, 22, 320-337.

Zayas, L., Gulbas, L. E., Fedoravicius, N., \& Cabassa, L. J. (2010). Patterns of distress, precipitating events, and reflections on suicide attempts by young Latinas. Social Science \& Medicine, $70,1773-1779$. 